\title{
O diálogo de linguagens \\ em semionarrativas do \\ B rasil, Portugal e África
}

Maria Lúcia Pimentel de Sampaio Góes 
Procederemos a breve reflexão sobre o Livro Objeto de Arte, Livro de Literatura Infantil e J uvenil de Literaturas de Língua Portuguesa. Para proceder-se à leitura dessa intertextualidade propomos um procedimento metodológico, que denominamos "leitura perceptiva intertextual". Procedimento que pode ser sintetizado;

INTEGRANDO SENSAÇÕES E ASSOCIANDO PERCEPÇÕES: PRODUZINDO SIGNIFICAÇÃO - a partir de nossa sensibilidade e da ativação de nosso equipamento humano (em alerta), os cinco sentidos e o intelecto interagindo. Não é necessário (embora louvável e precioso) domínio sobre os códigos extraliterários, como por exemplo, a História da Arte, as Técnicas de Pintura, Fotografia, enfim, artes visuais, sonoras e outras. A prática será a grande aliada deste procedimento.

\section{Introdução}

OBJETO NOVO seria o livro de Literatura Infantil e J uvenil em prosa ou poesia, que concentra linguagens de natureza vária e complexa. Tais livros constituem uma vertente muito rica ao lado dos livros só imagem ou só verbal, ou mesmo ao lado daqueles em que a ilustração aparece com função, apenas, ornamental ou referencial. 
Carlos Reis (1988) conceitua:

O conceito de leitura pode ser encarado sob diversas perspectivas teóricas e abordado sob diferentes prismas metodológicos, da sociologia da leitura à teoria da comunicação, passando pela psicolinguística, pela teoria do texto e pela estética da recepção.

Trataremos, aqui, da leitura em termos genéricos (sem prejuízo da pluralidade acima referida) entendendo o conceito de leitura, neste momento, como "operação pela qual se faz surgir sentidos no texto, tendo o leitor como coprodutor ou co-autor do texto por ser ele quem concretiza e se apossa desses sentidos

Citando Cohen (1982):

Fatores de ordem semionarrativa que condicionam o texto narrativo (narratividade), mas também as circustâncias psicológicas e socioculturais que usualmente envolvem a leitura da ficção narrativa. [...] Consuma-se a conexão "dos textos literários com os atos humanos básicos, com as fontes da linguagem e da nossa humanidade".

Por isso mesmo Ler é um debruçar-se, explorando os próprios sentimentos, examinando as próprias reações através da relação que o texto oportuniza. 0 texto ficional (literário e artístico) o faz de forma lúdica possibilitando o aprendizado em que as situações do mundo real não oferecem, antes, bloqueiam, traumatizam ou subvertem. O aprendizado a partir da relação leitor-texto parte dos aspectos sensoriais (ver, ouvir os símbolos lingüísticos); dos aspectos emoci onais (identificar-se, concordar, discordar, repelir, apreciar); dos aspectos racionais (refletir, analisar, correlacionar, interpretar, criticar).

Antonio J osé Saraiva (1974) nos auxilia lembrando que:

A arte nasce da realidade, desprende-se da realidade e renasce na realidade. Só a existência subjetiva da emoção prova a existência objetiva da obra de arte.

F ischer (1971) completa:

A arte é necessária a fim de que o homem possa conhecer e transformar o mundo. Mas é igualmente necessária em virtude da magia que lhe é inerente.

7. E. B enveniste, “A subjetividade na linguagem”, 1956, p. 258-65, apud aulas-apostila Fiorin.

8. Groupe U - F rancis E deline; J ean-M arie K linkenberg \& Philippe M inguet, Traité du signe visuel. Pour une rhétorique de l'image, Paris, É ditions du Seuil, 1990, p. 16. 
Portanto, a leitura como desenvolvimento da percepção dos sentidos trabaIhada pela reflexão é nossa proposta neste confronto, onde o Olhar é espaço de Acontecimento.

A recepção supõe o repertório do leitor e sua atuação reflexiva sobre o referido Objeto N ovo. R esulta em M etalinguagem ou Leitura M etalingüística. M uitos dos sentidos do texto dependem para sua revelação / desvelamento da produção de sua leitura. R efletir sobre o objeto livro, na Literatura Infantil tradicional, atrelada à pedagogia, tinha como pressuposto a criança / jovem leitor passivo. A estória infantil era vista como processo de levar através dela informações de toda ordem. Hoje, o livro infantil sabe-se Arte, Literatura e passa por modificações introduzidas por outras tecnologias, indo da linguagem dos quadrinhos à dos meios eletrônicos. O texto, objeto real, com linguagem verbal, visual e grafotipográficas, extrapola o Invólucro Físico T radicional. E sse OBJ ETO NOVO toca nos sentidos do equipamento humano: olhos, ouvidos, tato, paladar, via palavra, via imagem, via texto, via textura, via jogo.

Lemos hoje os sentidos da leitura cuja história é o chamado contexto sócioeconômico-religioso-artístico, etc. Os textos vivem em INTERTEXTUALIDADE. Tenho que ler a sala, o real, o conflito palestino-judeu, os conflitos da terra, elementos-texto que vou cruzar, intertextualizar... um sobre o outro, formando uma tessitura, um tecido. Como leitor devo estabelecer uma hierarquia, mas esta, sem preconceitos, poderá levar à leitura da intertextualidade, o texto como organização de linguagens.

O professor, guia dessa aventura de descoberta, precisa colocar a criança ativa, participante, comunicativa

$$
\text { IMAGINAÇÃO =IMAGEM + AÇÃO }
$$

I magem que reconhece, conhecend o de novo. Se na Leitura Verbal segue-se o encadeamento lógico da estrutura frásica, a Leitura do Não-Verbal no dizer preciso de Lucrécía D’A lessio Ferrara (1986) exige: “visão /leitura, uma espécie de olhar tátil, multissensível, sinestésico."

Para finalizar esta introdução necessária para a apreensão da leitura que se segue, pensamos que muitos educadores impregnados por uma leitura-desvio da Psicologia da Aprendizagem, descritora dos estádios de desenvolvimentos das estruturas do pensamento, passam a considerar a criança um ser em formação dependente da "sabedoria do adulto" e estabelecem com ela, ou contra ela, uma relação autoritária e dominadora. Ora, como sintetizam Palio e Oliveira (1986):

Se Ihe falta a completa capacidade abstrativa que a capacite para as complexas redes analítico-conceituais, sobra-lhe espaço para a vasta mente instintiva, pré-lógica, inclusiva, 
integral e instântanea, que só opera por semelhanças, correspondências entre formas, descobrindo vínculos de similitude entre elementos que a lógica racional condicionou a separar e a excluir. Correspondências, sinestesias. Todos os sentidos incluídos.

A Literatura Infantil e J uvenil considera a criança um ser pleno, portanto seu acervo não se forma de obras que não respeitem a criança como leitor inteligente, crítico, participativo.

\section{Leituras em confronto - B rasil}

$\mathrm{Na}$ leitura tentativa de "descoberta dos sentidos" procura-se desvendar a dialética das linguagens, concentrando o que está disperso. No livro O Tucunaré de Luiz G ouvêa de Paula, ilustrações de Ciça F ittipaldi temos um resgate de forma, resgate parafrástico, de forma simples convertida em forma artística, pois foi instaurado o estatuto do narrador.

O elemento dominante, por nós escolhido para re-articular os demais na sua reconstrução estrutural é o contraste a nível da estrutura discursiva. No plano do conteúdo, duas categorias de base organizam o texto : O Tucunaré vs Piabinha. $O$ texto é paráfrase, pois segue o paradigma fabular utilizando a semelhança cuja temática é o confronto entre o forte contra o fraco; neste ei xo de similaridade pode-se evocar como portótipo (texto base ou intertexto) deste tipo de fábula a conhecida "O Lobo e o Cordeiro".

Diagramação, desenhos expressivos com linhas, formas e cores em jogo denso de significados, compõem esta semionarrativa texto de leitura sem-idade, mas com a especificidade de poder ser lido, também, por crianças pequenas. Estas o farão a partir de seu repertório, porém provocadas pelo Objeto Arte, permitindo o reconhecimento de fatos, seres, objetos e a descoberta do novo, que brota das articulações específicas dessa singularidade.

A semionarrativa compõe-se de segmentos visual e semanticamente desenvolvidos linearmente, um antes $x$ um depois, em jogo tensional crescente até seu

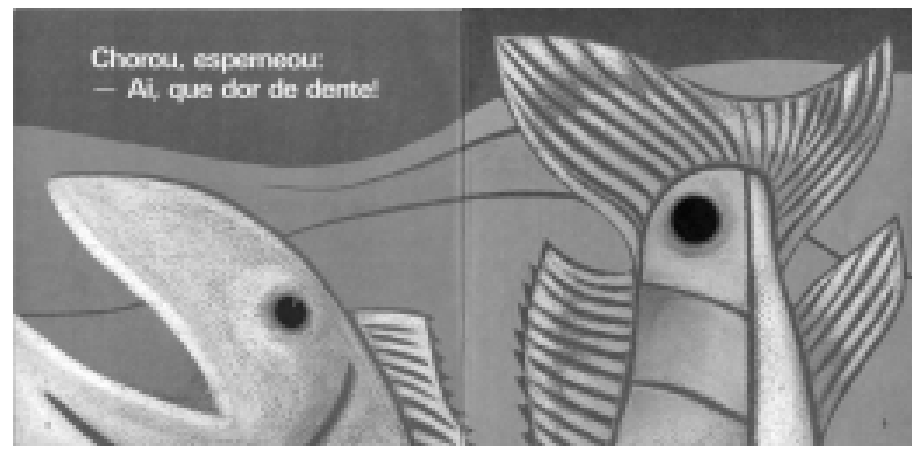




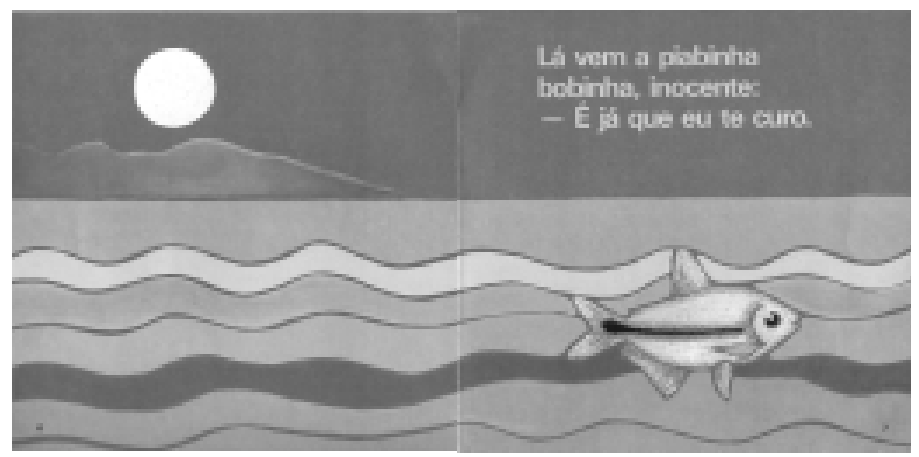

climax. O leitor, agarrado pela força dessa concentração artística de linguagens, é levado a refletir, a reconhecer (o que exige introspecção) para, então, tirar suas conclusões.

Os dois eixos do Sujeito estão em relação de contradição:

$\mathrm{S}$

Tucunaré

peixe grande

boca grande

masculino $\underline{s}$

Piabinha

peixe pequeno

boquinha

feminino

O S (Tucunaré) é o eixo do complexo e compreende S1 e S2.

$$
P N=F(S I>(S 2 U O V)
$$

O Programa narrativo, nível das estruturas narrativa, organiza-se já do ponto de vista dos sujeitos actanciais. Neste texto, o Sujeito Tucunaré e o Sujeito Piabinha. Não se nega / afirma conteúdos, mas trata-se de competência, de perfórmance; de transformar, pela ação do sujeito, estados de liberdade ou de opressão. Desenvolvem-se os temas, concretizados por meio de figuras:

I. tema da imposição, a presença arrogante, a postura de dominador do Tucunaré.

2. tema da fragilidade, identificada pelo feminino, pelo físico delicado.

3. tema da falsidade (toda a armação enganadora, o ardil do Tucunaré).

4. tema da posse (o fraco é engolido pelo forte).

Prosseguind a a leitura inicial, o verbal "O Tucunaré bocona gulosa" (T. p. 3) está grafado na cor rosa, enquanto todo o texto está em tonalidade verde claro (destacando-se, por sua vez, do verde mais profundo em mancha icônica remetendo a rio); a oposição das cores dotando de maior impressivividade o significado, na leitura da linguagem grafo-tipográfica (não-verbal), quer de per si, quer no eixo relacional. Para mim, não deve ser lida, apenas, a nível expressional (o que também deve ser feito a seu momento), mas a nível de conteúdo, neste programa 
narrativo, em que ardil mais do que sugerido, fica, assim, mais explícitado. O leitor pequeno ou o pré-lei tor, o leitor iniciante ou o leitor em processo de qualquer idade não pode equivocar-se. O tucunaré levou a piabinha na prosa. Somou à sua força, uma grande esperteza. Neste início presentificam-se os índices de tudo o que se seguirá. $O$ verbal reitera, a Piabinha carrega no nome a marca da fragilidade, desde o diminutivo metonímico até a oposição feminino vs masculino, indiciando a desigualdade de forças, não só de espécies diferentes, antes de um peixão vs uma peixinha.

A ilustração é impactante, a imagem do tucunaré, bocarra aberta, cabeça e parte avantajadas do corpo, fora da água, parte submersa, ( T, p. 4-5), só o rabo, de amplas dimensões, visível. O oculto adensando a impressão de força. Sob a dimensão icônica, subjaz uma intencionalidade de delineamento nítido do Confronto Força vs Fraqueza, Poder vs Fragilidade.

Acompanhando-se o ardil, o verbal "ele chorou, espemeou gritando seu $\mathrm{A} i$ “de terrível dor de dente!" (T, p.5-6). A mancha gráfica de fora-a-fora (página dupla) amplia o tamanho do tucunaré. Contrastando, a piabinha mínima, ocupa reduzido espaço. O emprego reiterativo do diminutivo: "piabinha, bobinha, inocente" (T, p. 6-7), (convicta de que poderia ajudar) dizendo: “-É já que te curo."

A imagem desfilando a paisagem-percurso seguido pela inocentinha. Uma Lua Cheia transmite a serenidade e a claridade mais que suficientes para que ela enxergasse para onde se dirigia; o rio simétrico, mas esses fatores (positivos) são por ela utilizados contra si própria; se por um lado denotam a transparência de suas intenções, isto é, sua confiança, credulidade e ingenuidade, por outro facilitam a perfórmance de seu manipulador. Ao virar da página, ( T, p. 8-9) , o impacto produzido em combinatória perfeita entre verbal e não-verbal: vermelho forte, depois escuro, de uma SETA GIG ANTE. Sinal convencional de direção, representação icônica, (achado feliz da ilustradora) é síntese perfeita do irrremediável ca-

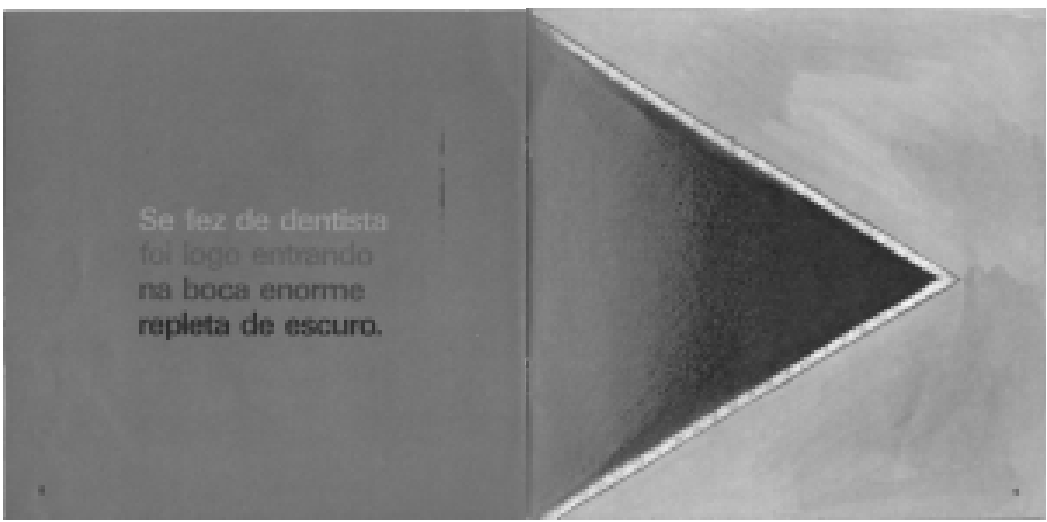




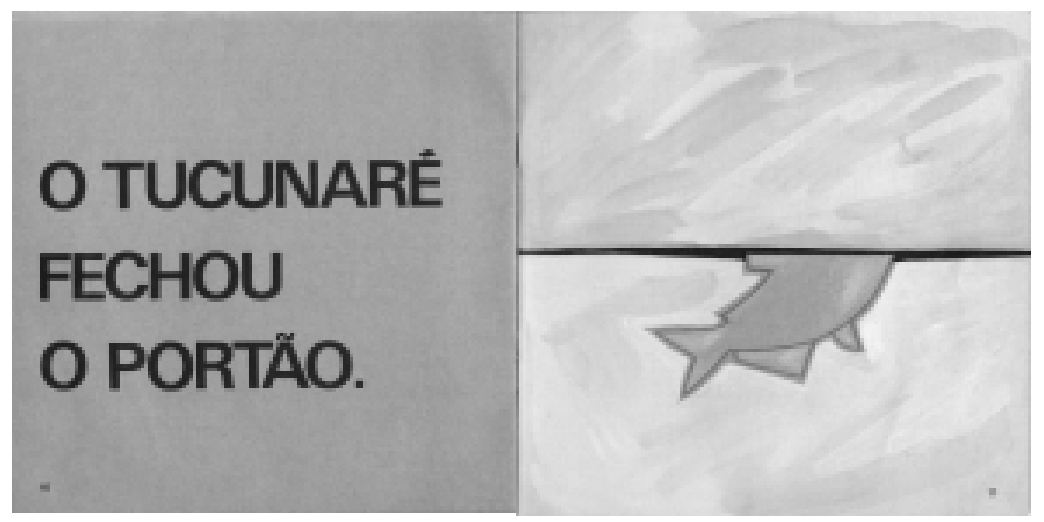

minho da Piabinha. O verbal, em segundo plano, permite ao leitor iniciante desvelar a imagem, ao ler a quadra:

Se fez de dentista

foi logo entrando

na boca enorme

repleta de escuro.

Ao nível sintático semântico: "O tucunaré fechou o portão". Declaração conclusiva: para a vítima, não haveria retorno. Os códigos visual e grafotipográfico, em tipos enormes (letras de dois centímetros de altura), caixa alta em negrito. A piabinha, sem cabeça, o risco negro indicando a linha de encontro da mandíbula fechada que a engueira. J á avançando para o "nível discursivo".

A "Seta Gigante" introduz tensão excessiva sob dois pontos de vista aspectuais: sujeito do fazer, sujeito de estado.

Para a Piabinha, a ruptura do contrato "Fechou o portão" (figura dos dentes, arcadas dentárias, é instântanea com o estado "Crise de confiança"- que com - figura (configura-se) ou é figurativizada pela metáfora " fechou o portão" (verbal) e a imagem aquática cortada ao meio ( $T, p .11)$ pela linha horizontal negra e a silhueta da piabinha sem cabeça, esta claramente sendo engolida, devorada. Por quem? (T, p. 10) O verbal em negrito, letras em grau aumentativo absoluto, taxativo: "O TUCUNARÉ FECHOU O PORTÃO". Ou o " sentido de malevolência" é o do destinador Tucunaré.

O texto utiliza o recurso semântico da ancoragem (nível do conteúdo) iconizando-se pela linguagem-não-verbal (e não apenas a nível expressional) pela presença total no texto, por exemplo do ícone-rio.

O enunciador Tucunaré construiu um disposi tivo veredictório ao chorar "A $\mathrm{i}$, $A{ }^{\prime \prime}$ e afirmar terrível dor de dente. O enunciatário (Piabinha) ouviu o choro e 
convenceu-se e interpretou o lamento, como urgência de seu agir. O "Ai,Ai" instaura o actante (eu-T ucunaré) como um sofredor / vítima de grande dor, trazendo implícito a disjunção em outra temporaiidade (mais um pouco de tempo) em nãovítima e sim e um assassino (devorador). Sua ação? Se fez de dentista! O enunciador criou efeitos de verdade (embora na categoria ser-parecer), na enunci ação enunciada ( $B$ enveniste, 1956). O Tucunaré enunciador conseguiu o efeito de dissimulação.

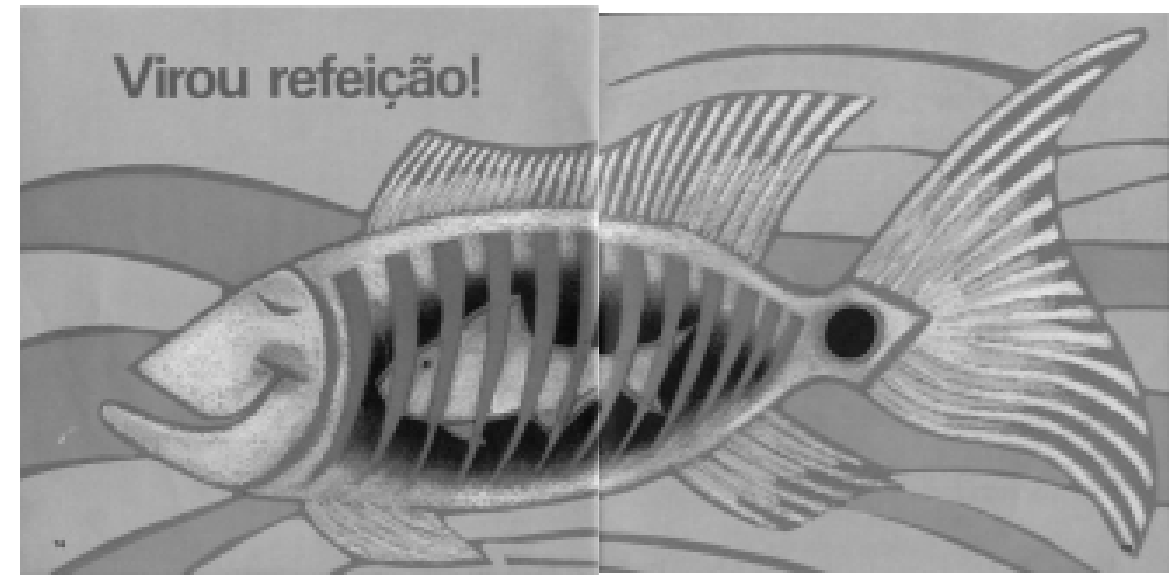

Ainda deve-se referir a modalização veridictória ao fazer interpretativo, focando a manipulação, envolvendo o ser e o parecer. As duas modalidades veredictórias:

$\begin{array}{lll}\text { ser } & \times & \text { parecer } \\ \text { não parecer } & \text { não ser }\end{array}$

Tucunaré parece para Piaba um amigo, leva-a a fazer algo, portanto, esse fazer-fazer é de ordem cognitiva e leva, também, a fazer algo de ordem pragmática (entrar em sua boca) e "FECHOU O PORTÃO" e a Piabinha

\section{“VIROU REFEIÇÃO “}

R egistra-se a embreagem (retorno à instância da enunciação) instaurada no interior do discurso por uma marca criadora de efeito de sentido. Não mais o discurso direto, mas a terceira pessoa do singular no lugar da primeira. Deslocou-se a subjetividade dos falantes (Tucunaré e Piaba), ele fechou o bocão, ela virou refeição. Como na fábula do "L obo e do Cordeiro", a força saiu vencedora. Enquanto o Lobo não manipula, apenas tenta argumentar, mas é derrotado pelo Cordeiro, então, revela-se integralmente; Tucunaré simula "não parece, mas é assassi- 
no". M etáforas e M etonímias como figuras do discurso na interação dos códigos. Assim, a Piaba no estômago do Tucunaré = metáfora da devorarão dos poderosos, quando utilizam argumentação falaciosa para obter suas refeições e satisfazer sua fome insaciável. Os inocentes ingênuos seguindo a seta gigante, como "gado para o matadouro". As figuras verbais e não verbais como conectores de isotopias; as conexões feitas por polissemia.

- A nalisado o plano do conteúdo, é chegado o momento da reflexão sobre o plano de expressão. Quando se trata de texto com função estética, como acontece com o livro O Tucunaré, o autor ou co-autores recriam o viver através das palavras, na linguagem verbal, pela imagem nas artes gráficas ou plásticas, pela utilização do espaço, na diagramação, pela fotografia na arte respectiva, pelo som, nas artes de estruturas auditivas (música, cinema), enfim, lembrando:

Par ailleurs, les historiens des arts (art du charpentier comme de l' architecte) nous rappelleront que le terme pictura, aux temps modernes, avait une extension bien plus grande que I'usage du terme au XXe. siècle. I is savent que le domaine de la peinture a été considérablement plus étendu dans son emploi classique, c'est-à-dire avant la formation de l'expression funeste beaux-arts (d'ailleurs tout à fait périmée dans le vocabulaire technique de l'esthétique contemporaine; (1990, p. 16).

Estamos longe de pretender já caminhar no campo de uma "teoria da comunicação visual", porém, há muito tempo, bem mais do que uma década, o artefato literatura infantil / juvenil de vanguarda, avança a passos de gigante tendo como suporte os signos icônicos de linguagens não-verbais. Assim, no momento, estamos lendo as obras de M erleau-Ponty, que recorta a experiência de percepção a partir da fenomenologia. Nossa preocupação cresce por saber que o professor já formado ou em formação, o é quase que unicamente na leitura do verbal. Procuramos insistir em que não pode continuar desconhecendo os demais signos presentes no objeto novo, livro de literatura infantil / juvenil de vanguarda, pois este estará sendo lido redutoramente (no mínimo). Propomos que confiem e se exercitem em sua percepção, em sua sensibilidade vendo e lendo o que se increve na obras que se oferecem a nosso olhar. A criança, o jovem já lêem assim...

Transpondo o limiar das leituras J ulia K risteva ${ }^{10}$ opõe-se a qualquer reducionismo analítico ou interpretativo:

O termo "intertextualidade" designa essa transposição de um ou (vários) sistema(s) de signos noutro, mas como este termo foi freqüentemente tomado na acepção banal de "crítica das fontes" dum texto, nós preferimos-Ihe um outro: transposição, que tem a vantagem de precisar que a passagem dum a outro sistema significativo exige uma nova articulação do estético - da posicionalidade enunciativa e denotativa. (K risteva, 1974, p. 60) 


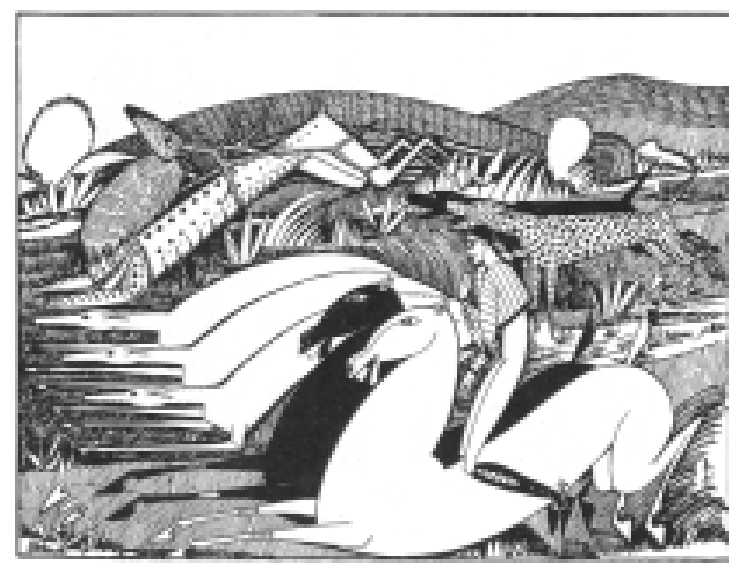

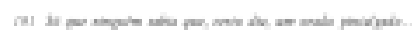

\section{leituras em confronto: Portugal}

Hi stórias em Ponto de Contar, sobre desenhos de A madeo de Souza-Cardoso, em parceria de Antônio Torrado e Maria Alberta M enéres. As estórias do livro foram inspiradas nos desenhos de Sousa-Cardoso (1887-1980) participante da revolução plástica do início do século que gerou os movimentos como futurismo, cubismo e abstracionismo. Colorista ardente, associou as experiências da cor com os motivos folclóricos de sua terra natal. Portanto, o verbal nasceu do diálogo inter-textos, quadros de pintura leitura-fantasia neles inspirados. A técnica, desenhos em tinta-da-china (nanquim) onde percebem-se sugestões orientalizantes e traços da tapeçarias medievais. Os autores partem dessas sugestões implícitas dos desenhos tornando-as comunicáveis aos receptores infantis, através da fantasia da narrativa. E ntre as estórias escolhemos para esta reflexão a "História do

\section{Reino Pintalgado".}

Trata-se de um contar do tempo em que o mundo era mais liso. Mas em coisas de pintura sempre sobram uns tantos salpicos. Inventaram que ter pintas era sinal de nobreza. E o mundo construido para isolar as diferenças ruiu. O reino dividiu-se entre "os já sarapintados e os que também queriam ser sarapintados". As gentes desta terra julgou-se superior às de outras e estabeleceu proibições: "nada de estranjeiros! evitem - se os contágios!"

Entretanto surgiram os burladores dessas determinações, leia-se o texto:

Só que ninguém sabia que, o rei e a rainha, disfarçados e não obedecendo às suas próprias ordens, gostavam de fugir a cavalo do cerco das muralhas, que eles próprios tinham construido, e cavalgar noite dentro, salpicando de coelhos espavoridos o matagal 
Foi assim que pinta aqui, pinta acolá, tudo ficou pintalgado com:

pontos e pontinhos, pintas e pintinhas, manchas e manchinhas... tão diferentes do mundo liso princípio desta história.

No texto acima, a Dominante, elemento estrutural da narrativa, também é o contraste, a oposição separando os homens, alijando os menos possuidores dos privilégios, dos poderes dos que detém a Força. Esta entendida lato sensu, motivo gerador de castas, classes, hierarquias autoritárias, opressões, enfim, tudo o que o Homem inventou, inventa para não respeitar os direitos do Outro, visto quem quer que seja ele, como um Diferente. Quer se argumente ficar a diferença por conta da raça, religião, costumes, idéias, partidos, crenças, nacionalidades ou qualquer outro sinal distintitivo. Muitos dos que levantam a bandeira da igualdade foram responsáveis por brutais e odiosas discriminações e ainda o são. Não há diferença entre o maniqueísmo de vanguarda (calcado em valores atuais) e o dos falsos moralistas, venha o patrulhamento ideológico de onde vier. Ele sempre gera fanatismos que se não martirizam em fogueiras da Inquisição, o fazem no abrasamento das paixões. Só líderes da estatura de um Mandela, mesmo aprisionado, humilhado por anos e anos, tem a clareza, a grandeza de lutar pela igualdade e fratemidade e não pelo Poder. A narrativa do R eino Pintalgado é metafórica, simbólica pois é representação de um geral; mas o que a toma texto estético é o delicado trabalho artesanal de linguagem em belíssimo contraponto com os desenhos de A madeo de Sousa-Cardoso produzindo ressonâncias sensíveis, éticas e estéticas em leitores fluentes e críticos

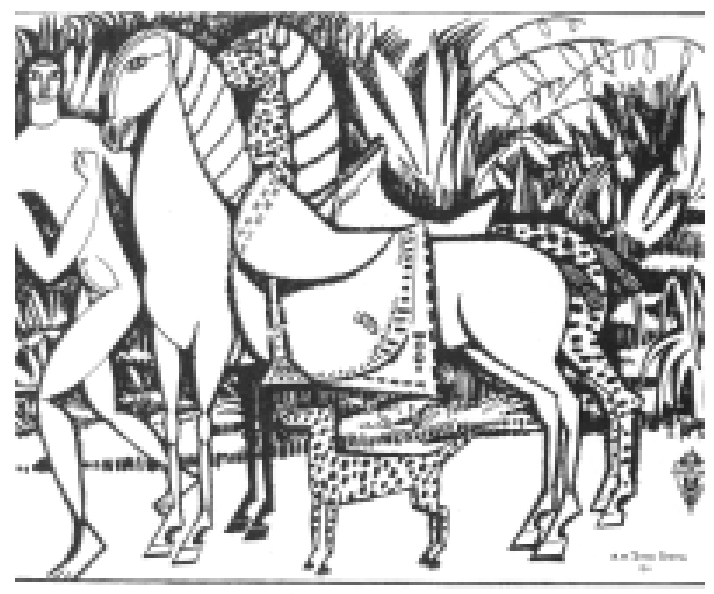




\section{Leituras em confronto: África O pais de mil cores de Octaviano Correia}

Nessa estória de um país onde os homens não tinham cor, o Contraste permanece como Dominante estrutural. A narrativa principia pela enumeração de componentes da natureza, plantas, bichos, portanto, da terra, do ar, onde até o tempo era colorido. Os homens não.

ninguém notava e todos eram felizes

Pode-se apontar para a oposição: ninguém vs todos; significando cada indivíduo 'de per si', e a coletividade como um todo.

O código visual + grafotipográfico é complexo, variado, permitindo uma multiplicidade de leituras. A página dupla inicial tem a cor Branca predominando. Aliás, a primeira é toda em branco, já na segunda a brancura é interrompida pela letras e por um círculo colorido (ícone metaforizando, em gradação crescente - Planteta / Terra / País). Os diversos significantes presentificam-se através do tipo de letra (caixa alta + maiúsculas e minúsculas), igualmente em distribuição espacial relacionando significante e significado. $O$ resultad o é poesia concreta em jogo semântico de figuras sonoras, visuais e verbais.

A seqüência altera a harmonia anterior por uma ruptura em inversão: os homens coloriram-se, a natureza, a cultura e os valores perderam cor e felicidade.

A linguagem visual estabelece a ausência da cor, na representação do homem e da paisagem, como índices de tristeza e de carência. Os agentes da ruptura são apontados: os patrões da guerra e da morte a devorar as cores dos pássaros, da madrugada e tantas coisas mais. Foram engolidos: a justiça, a alegria e a paz.

O código visual em imagens impressivas, conotando transparência, exige um leitor de olhar tátil, sensível e perceptivo.

A ausência de figuras e de cor é substituída por gradação crescente de imagens coloridas, até sua superposição que encerra a primeira parte da narrativa. Novamente, a configuração espacial, onde o branco assume total presença. Primeiramente iconiza a transformação do País das Mil Cores em PAÍS TR ANSPARENTE. Estabelece, então, a oposição branco vs vermelho; este surge no ar em "manchinha vermelha pequenina" ... a adversativa carregada de intecionalidade " mas VER ME L HA". ( A caixa alta, o negrito enfatizand o o código da cor vermelha).

A narrativa avança sempre utilizando o espaço, o tipo de letra, a diagramação para significar, exindo um olhar atento e perceptivo. O leitor, não afeito a essa exigência de concentração de linguagens, compreenderá o mínimo desse texto, perdendo-o como obra aberta e densa. 
A oposição-luta entre os dominados e os patrões da guerra e da morte começa a inverter a situação. Os patrões mandaram lavar a manchinha:

ESFREGARAM A MANCHINHA VERMELHA

RASPARAM A MANCHINHA VERMELHA

PRENDERAM A MANCHINHA VERMELHA

FUZILARAM A MANCHINHA VERMELHA

O verbal por essa reiteração em paralelismo, em isomorfismo léxico, sintático, semântico, em aparente transparência deflagra, em código metafórico subliminar, todas as opressões do HOMEM CONTRA O HOMEM.

A adversativa seguida da marca temporal, "mas na manhã seguinte", precipita o segmento final e o clímax narrativo. A tessitura concentra-se, o código visual prevalecendo, com a manchinha a crescer a cada dia (e a cada nova representação em imagem).

Homens sem cor erguem um bebê vermelho e seus dedinhos tocam a avantajada mancha vermelha. Os sentidos da metáfora visual poderiam ser elencados:

VERMELHO / SANGUE / PARTO / NASCIMENTO / VIDA /

A gradação do vermelho engolindo tudo e todos, até que toma totalmente o centro da página dupla : no seu eixo, escrito em negrito somente a palavra VERMELHO. Ao canto esquerdo, um homem, uma mulher e uma criança em abraço de união e de amor.

A próxima imagem mostra uma corrente humana, os grilhões caídos (no visual); o verbal contando que os homens tinham aprendido ser o Vermelho a cor da LIBERDADE e a elegeram a sua cor, prontos a morrer por ela.

O troar dos canhões fôra abafado e nunca mais ouvida a Voz dos patrões. $O$ recurso grafotipográfico bradando:

\section{DE NENHUNS PATRÕES}

O uso pouco comum do indefinido variável tornando definitiva a exclusão de qualquer veleidade patronal. O movimento circular introduz, novamente, a Primeira Página do Livro.

Depois a sentença:

\section{E O PAÍS DAS MIL CORES COMEÇOU A CHAMAR-SE MUNDO} senão vejamos:

Verde $=$ símbolo da Esperança, ícone da natureza. 
Rosa Vermelha $=($ lua e amarelo $)$ ícone da Libertação de Angola e da Libertação do Homem.

Família Negra $=$ Símbolos da Luta contra a Opressão.

\section{Símbolo do Não a Nenhuns Patrões.}

Metonimicamente, a luta do Negro contra o Branco Invasor é metaforizada para a luta do oprimido vs. opressor e alegorizada para a libertação do Homem e, portanto, do M undo. Concluindo o Livro Objeto Arte de Literatura Infantil e J uvenil de Língua Portuguesa por sua metalinguagem e intertextualidade (articula signos verbais e nãoverbais), em

"sobrecodificacões discursivas que inter-agem".

no dizer de B enjamin Abdala J únior: (1989):

As adesões político-sociais do escritor participante não podem prescindir da criatividade. Por uma práxis mais dialética, ele adquire modelos articulatórios mais abertos que, num movimento inverso - da obra de arte para a vida - pode permitir-Ihe inserção mais funda na própria vida social.

Esperamos por esta tentativa de leitura ter demonstrado que a Literatura Infantil e J uvenil é um dos tons da harmonia do "canto coletivo da Literatura Engajada Portuguesa" e um dos fatores que levam a considerar a existência de um macrossistema literário em português na proposta de Benjamin Abdala J únior.

\section{Síntese do confronto}

O texto brasileiro poderá ser fruído por qualquer leitor com sensibilidade, preferencialmente, pelo leitor infantil, por sua dimensão lúdica.

A seqüencialidade passa do nível do " fingimento" do Tucunaré iludindo a Piabinha I nocente para o aprisionamento dela e sua devoração. A díade oposicional pontificando:

$\begin{array}{ccc}\text { forte } & \text { vs. } & \text { fraco } \\ \text { esperto } & \text { vs. } & \text { inocente } \\ \text { vida } & \text { vs. } & \text { morte }\end{array}$

O texto de Portugal, 'E stória do Reino Pintalgado', poético, revela em nível profundo a oposição entre igualdade vs. diferença. $O$ mergulho metafórico faz aflorar os meandros do "profundo humano" : a cobiça, o desejo de superioridade, estar além e acima dos demais, enfim os n motivos geradores de castas, rejeições, ódios, guerras. 
O texto angolano O País das Mil Cores descreve a transformação de um mundo ideal para um mundo brutal-mortal. Os patrões de guerra e de morte triunfando até a aparição de um Símbolo, a MANCHINHA VERMELHA. Esta alarga-se até configurar-se em Alegoria.

A M ancha Vermelha instalará o desejo de luta, de revolta, de insubmissão, a ânsia do Não, a vontade de ser livre.

No contexto espacial do texto angolano, os significados apontam para a luta de libertação, esta assumida pelas facções políticas. Penso, porém, que o autor conseguiu do particular atingir o universal, pois o fato de $\mathrm{H}$ omens sem Cor erguerem um B ebê Vermelho, seus dedinhos tocando a já I mensa M ancha Vermelha fez o seguinte percurso:

VERMELHO /SANGUE / PARTO / NASCIMENTO /VIDA

Aspiração máxima humana Vida Livre exige Nenhuns Patrões.

Concluindo em síntese gráfica:

texto brasileiro $=$ forte vs. fraco

metafórico lúdico

Díade oposicional

texto português $=$ superior vs. inferior

Forte vs Fraco

metafórico-poético- simbólico

texto angolano $=$ patrões do Poder vs. vítimas

metafórico alegórico

\section{R eferências bibliográficas}

ABDALA J UNIOR, Benjamin. Literatura, histórica e política. São Paulo: Ática, 1989.

COHEN, R. The statements literaty texts do not make. In New literary history. 13 (30): 37991, 1982.

FERRARA, Lucrécia. Leitura sem palavras. São Paulo: Ática, 1986.

FISCHER, Ernst. A necessidadeda arte. Rio de J aneiro: Zahar, 1971.

GROUPE U (EDELINE, Francis; KLINKENGERG, J ean-Marie \& MINGUET, Phillippe).

Traité du signe visuel. Pour une rhétorique de l'image. Paris: Seuil, 1990.

KRISTEVA, J ulia. La révolution du langage poéti que, apud J ENNY, Laurent. A estratégia da forma. In Poétique n. 27. Intertextualidades. Coimbra: Almeida, 1979.

PALLO, Maria J osé \& OLIVEIRA, Maria R osa de. Literatura infantil. São Paulo: Ática, 1986.

REIS, Carlos \& LOPES, Ana Cristina. Dicionário de teoria da narrativa. São Paulo: Ática, 1988.

SAR AIVA, Antonio J osé. Ser ou não ser arte. Póvoa do VArzim: Publicações E uropa-América, 1974. 